\title{
LABORATORY TESTS OF UNIFORM FABRIC IMPREGNATED WITH MITE REPELLENTS
}

\author{
Professor D. S. BERTRAM; D.Sc., F.I.Biol. \\ Mr. R. C. PAGE, A.I.Sc.T. \\ London School of Hygiene and Tropical Medicine \\ Colonel A. J. MOSS-BLUNDELL, \\ M.B.E., M.A., M.B., B.Chir.(Cantab.), D.P.H., D.T.M.\& H., late R.A.M.C. \\ Army School of Health, Ash Vale*
}

\section{Introduction}

Personal protection against infestation with mites, and ticks, and particularly against infection of military personnel in the Orient with scrub-typhus transmitted by trombiculid mites, has for many years depended largely on treating clothing with repellent, acaricidal, chemicals. The pioneer studies of numerous investigators concerned with the health of British, Australian and American forces in the Far East during World War II, reviewed by Dowling (1955), demonstrated the effectiveness of dimethylphthalate (DMP), dibutylphthalate (DBP) and benzyl benzoate, or mixtures of benzyl benzoate with DMP, or DBP, against trombiculid mites when applied by manual smearing or dipping of uniforms. Particularly with benzyl benzoate and DBP, protection persisted despite several launderings. Gilbert, Gouck and Smith (1955) reported on newer, insect repellents. Of these, $\mathrm{N}, \mathrm{N}$-diethyl- $m$-toluamide (DET, deet, metadelphene) proved outstandingly successful when applied to the skin as a mosquito repellent. Diethyltoluamide has since come into wide use and, like DMP, is one of the few repellents now available for military, and civilian, protection against biting pests (W.H.O., 1963; Smith, 1965; Gouck, 1966). Gilbert (1966) considers DET as the most efficient insect repellent, whether applied to the skin or clothing, of those in use at the present time. Markarion, Enos and Pratt (1965) describe biochemical methods for assay of DET, in connection with its success in a lanolin-based cream as a leech repellent. DET is now on supply as a general insect repellent in the British Army. Laboratory tests are reported in this paper on how effective DET is, compared with DMP or DBP, as a component with benzyl benzoate in repellent formulations for treatment of uniforms, of jungle green nylon/cotton material, against mite attacks.

\section{Materials and Methods}

A laboratory colony of trombiculid mites was not available; adult females of a culture of the Tropical Rat Mite, Ornithonyssus bacoti-reasonably convenient to keep in culture (Hawking \& Sewell, 1947; Bertram, Unsworth \& Gordon, 1946)-were used as test mites. The apparatus devised, and described below, resembles in principle that used by Granett and Sacktor (1947) for testing tick repellents with the tick Amblyomma americanum, but appears, at least with the rapid-running habit of $O$. bacoti, to be more satisfactory and sensitive. It demonstrates repellence in the sense of inhibiting, or preventing, mites from proceeding on to a treated fabric and not in terms of reducing the bite-or attachment - rate on a host which involves also acaricidal effects causing paralysis and death of mites after they are in contact with a chemically impregnated 
cloth. Since some mites do pass on to repellent-treated garments, paralysis on contact was taken as the basis of assessment of the efficacy of protection by Snyder \& Morton (1947), and others, in laboratory tests with trombiculid larvae. Likewise, repellencies were rarely completely successful in the present tests; some subsidiary observations were, therefore, also made of the acarididal properties of the impregnated fabrics.

In field trials, the separate contributions of true repellency and of acaricidal effect on contact in reducing the bite-rate of mites, or ticks, are not usually, and inevitably so, differentiated. This involves a wider connotation to the concept of repellence in mite, or tick, infestation control than is applied, as discussed by Dethier (1956), Hocking (1964) and others, to the deflection by a repellent substance of biting insects such as mosquitos from alighting and feeding on their hosts.

\section{The Apparatus}

The apparatus (Fig. 1) consisted of a $15.3 \mathrm{~cm}$. square base-plate of $5 \mathrm{~mm}$. steel, a thinner $(1 \mathrm{~mm}$.) overlay plate, also of steel and $15.3 \mathrm{~cm}$. square, which had cut out of it centrally a circular area of $13 \mathrm{~cm}$. in diameter. The third component was a circular disc, $5 \mathrm{~cm}$. in diameter, of stainless steel $3 \mathrm{~mm}$. thick, with a central pit, $1 \mathrm{~cm}$. in diameter

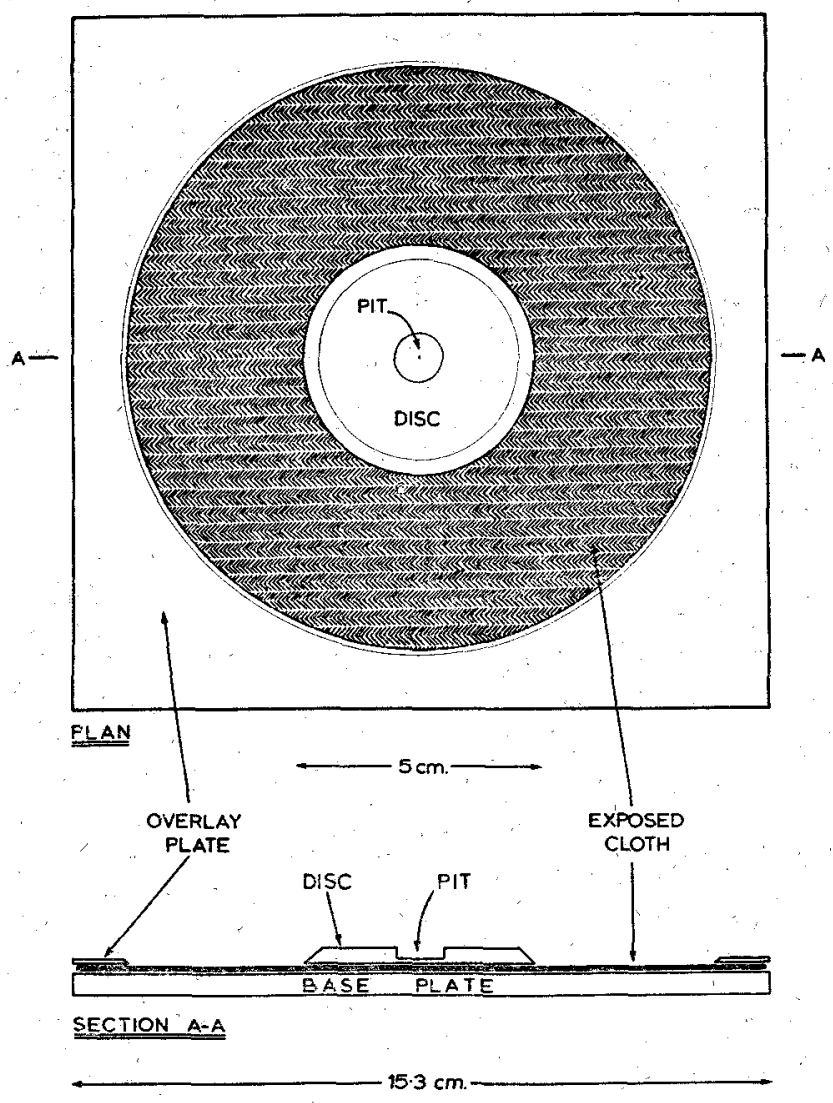

Fig. 1 Plan and section of apparatus for determining repellence of mites ( $O$. bacoti) by repellentimpregnated cloth 
and $2 \mathrm{~mm}$. deep. The sides of the pit were vertical; the outer edge of the disc and the inner edge of the overlay plate were chamfered at $35^{\circ}$.

For a test, a patch of fabric, $15 \mathrm{~cm} . \times 15 \mathrm{~cm}$. was put flat on the base-plate and the overlay plate placed on top, thus exposing the fabric through the large circular area of the overlay plate. The disc was now placed, pit upwards, in the centre of the exposed area of fabric.

Mites already collected into a wool-plugged glass tube, $8 \mathrm{~cm} . \times 1 \mathrm{~cm}$. diameter, were released into the pit; $10-15$ female mites per tube is a convenient number.

The mites run out of the pit and across the disc and, unless prevented by a repellent effect of a chemical impregnated in the fabric, pass on to and across the fabric to the perimeter area of the overlay plate, and beyond. A 5 minute period was taken as the duration of a test, as virtually all mites disperse across untreated, control, cloth within this period. Besides a control, mites were released also on other units set up simultaneously but with a treated cloth beneath the overlay plate. With treated fabrics, the number of mites remaining on the central disc at the end of 5 minutes provided the measure of the repellency by the impregnant formulation.

The tests were done in an insectary of moderate humidity, and at $25^{\circ} \mathrm{C}$., with overhead artificial light.

\section{Repellents and Treatment of Fabrics}

Concentrates were prepared of 10 parts emulsifying agent (ethylan), 45 parts of benzyl benzoate and 45 parts of either DMP, DBP or DET. Samples of the nylon/cotton material, about $15 \mathrm{~cm} . \times 15 \mathrm{~cm}$. were dipped to saturation in a 5 per cent aqueous dilution of one or other of the three concentrates ( 1 part concentrate to 19 parts of demineralised water), and allowed to dry: For each formulation, one sample was not further treated, one was washed once, another twice and a fourth on three occasions. Each wash was in detergent-free soap in hot water $\left(40^{\circ} \mathrm{C}\right.$.); the materials were allowed to dry between washes. These procedures simulated simple methods of impregnating and laundering likely to be practicable for troops under operational conditions.

In addition, other samples of the cloth were treated by immersion for 1 week in undiluted DMP, or in undiluted DET, or by dipping briefly as for 5 per cent benzyl benzoate and a $2 \frac{1}{2}$ per cent benzyl benzoate-ethylan emulsion in water.

Treated cloths were kept separate in flat polythene envelopes except during the trials. Although 5 trials were, for unavoidable reasons, spread over 17 weeks this method of storage appears to have ensured that the initial condition of the treated cloths was well maintained. When finally exposed to an insectary atmosphere of $25^{\circ} \mathrm{C}$. and moderate humidity, all repellency was lost within 4 weeks.

Untreated nylon/cotton fabric was used for control tests.

\section{Results}

Repellence

In 36 control tests, using untreated cloth with 5 to 15 mites (mean - 10.7) per test, only 2 out of 388 mites ( 0.5 per cent) failed to cross the fabric during the 5 minute period. On the other hand, by inspection (Table 1), all 3 formulations of repellent, notwithstanding variability in the data, repelled mites in the 5 trials with considerable success not only after initial impregnation but after as many as three washings of the 
Table 1

\begin{tabular}{|c|c|c|c|c|c|c|}
\hline & \multirow{2}{*}{ Emulsion } & \multirow{2}{*}{$\begin{array}{l}\text { Trial } \\
\text { No. }\end{array}$} & 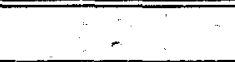 & \multicolumn{2}{|c|}{ Treatment of cloth after impregnation } & \multirow[b]{2}{*}{3 washes } \\
\hline & & & No wash & 1 wash & 2 washeश्र & \\
\hline \multirow[t]{2}{*}{; } & \multirow{2}{*}{$\begin{array}{c}5 \% \\
\text { benzyl benzoate } \\
\text { and } \\
\text { DMP } \\
\text { Total } \\
\text { Repellence } \\
106 / 124 \\
(85.5 \%)\end{array}$} & $\begin{array}{l}1 \\
2 \\
3 \\
4 \\
5\end{array}$ & $\begin{array}{c}8 / 9(88.9 \%) \\
8 / 9(88.9 \%) \\
8 / 12(66.7 \%) \\
12 / 12(100 \%) \\
3 / 10(30 \%)\end{array}$ & $\begin{array}{c}10 / 10(100 \%) \\
= \\
-\end{array}$ & 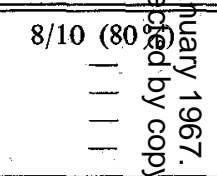 & $\begin{array}{c}10 / 10(100 \%) \\
9 / 9(100 \%) \\
10 / 10(100 \%) \\
10 / 12(82.5 \%) \\
10 / 11(90.9 \%)\end{array}$ \\
\hline & & Totals & $39 / 52(75 \%)$ & - & 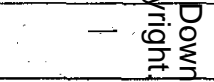 & $49 / 52(94.2 \%)$ \\
\hline \multirow{2}{*}{\multicolumn{2}{|c|}{$\begin{array}{c}5 \% \\
\text { benzyl benzoate } \\
\text { and } \\
\text { DBP } \\
\text { Total } \\
\text { Repellence } \\
100 / 126 \\
(79.3 \%) \\
\end{array}$}} & $\begin{array}{l}1 \\
2 \\
3 \\
4 \\
5\end{array}$ & $\begin{array}{c}6 / 10(60 \%) \\
8 / 10(80 \%) \\
7 / 13(53.9 \%) \\
11 / 12(91.7 \%) \\
9 / 12(75 \%)\end{array}$ & $\begin{array}{c}10 / 10(100 \%) \\
- \\
- \\
-\end{array}$ & 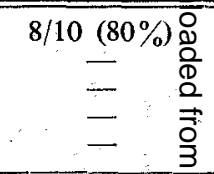 & $\begin{array}{c}6 / 7(85.7 \%) \\
9 / 10(90 \%) \\
10 / 10(100 \%) \\
6 / 9(66.7 \%) \\
10 / 13(76.9 \%)\end{array}$ \\
\hline & & Totals & $(71.9 \%)$ & - & - 喜 & $41 / 49(83.7 \%)$ \\
\hline . & \multirow{2}{*}{$\begin{array}{c}5 \% \\
\text { benzyl benzoate } \\
\text { and } \\
\text { DET* } \\
\text { Repellence } \\
171 / 281 \\
(60.9 \%)\end{array}$} & $\begin{array}{r}1 \\
2 \\
3 \\
4 \\
5\end{array}$ & $\begin{array}{c}2 / 9(22.2 \%) \\
14 / 18(77.8 \%) \\
4 / 12(33.3 \%) \\
15 / 20(75 \%) \\
12 / 23(52.2 \%)\end{array}$ & $\begin{array}{l}9 / 10(90 \%) \\
9 / 10(90 \%) \\
7 / 9(77.8 \%) \\
9 / 12(75 \%) \\
8 / 11(72.7 \%)\end{array}$ & $\begin{array}{l}4 / 9(44.4 \%) \\
4 / 10(40 \%) \\
5 / 11(45.5 \% \text { 吾 } \\
3 / 10(30 \%) \\
5 / 10(50 \%) \\
\end{array}$ & $\begin{array}{c}7 / 9(77.8 \%) \\
11 / 19(57.9 \%) \\
14 / 19(73.7 \%) \\
14 / 24(58.3 \%) \\
15 / 26(57.7 \%)\end{array}$ \\
\hline & & Totals & $47 / 82 \quad(57.3 \%)$ & $(80.8 \%)$ & $\begin{array}{r}21 / 50 \text { (42.0息) } \\
\end{array}$ & $61 / 97(62.9 \%)$ \\
\hline
\end{tabular}

Proportions, and percentages in brackets, of adult female Ornithonyssus bacoti (Tropical Rat Mite) îpelled in 5-minute tests in 5 laboratory trials of nylon/cotton, jungle-green, uniform cloth impregnated with emulsions differing in rontaining either DMP, DBP or DET (diethyltoluamide) and whether unwashed or washed 1-3 times after impregnation.

Denominator $==$ No. of mites in test; Numerator $=$ No. of mites repelled.

Denominators of 18 to 26 mites in DET tests denote two tests combined: 
impregnated cloth. Overall repellency appears to be best with DMP ( 85.5 per cent), intermediate with DBP (79.3 per cent) and least, but by no means negligible, with DET, (60.9 per cent). There was no significant difference by $\chi^{2}$ test between DMP and DBP, but DET was significantly less effective $(P<0.001)$ than the combined results for DMP and DBP. The relative efficacy of the three formulations was further compared for the repellencies of the unwashed and thrice-washed fabrics over 5 trials. DET, with repellencies of 57.3 per cent (unwashed) and 62.9 per cent (after 3 washes), proved significantly less effective (at the 5 per cent level) than corresponding cloths of DMP (75 per cent, unwashed; 94.2 per cent after 3 washes) or of DBP (71.9 per cent unwashed; 83.7 per cent after 3 washes).

Fabric soaked for 1 week in undiluted DMP, or DET, gave in 2 tests over 5 weeks, 96 per cent repellency with DMP and a lower repellency of 73 per cent with DET. As with the 5 per cent emulsions, undiluted DET again was less satisfactory.

An anomalous feature in the foregoing data for the three 5 per cent formulations (Table 1) is that the treated fabrics appear to be more effective after 3 launderings than when they had not been laundered at all. For DMP the difference between 75 per cent and 94.2 per cent is just significant at $\mathrm{P}<0.05$; the differences for DBP and DET are not significant. The behavioural responses of the mites probably influenced the results. With treated cloths, repelled mites showed varying degrees of hesitation and recoil at the top, or on the slope, of the chamfer of the central disc, or on coming close to, possibly touching, the impregnated cloth. The mites remained, however, on the central disc, repelled, at the final count. A particularly violent reaction was, however, occasionally observed with the stronger impregnations of DMP, less so with DBP, although not with any thrice-washed fabrics nor with DET at all. A mite became suddenly incoordinate at the top of the disc chamfer and tumbled down the slope on to the impregnated cloth. It resumed running immediately, either returning to the disc or going out further on to the cloth, and, usually in that event, across it to the perimeter. Such mites were, by the nature of the test readings, recorded as unrepelled although rather erroneously as they had reacted sharply to the repellent, apparently its vapour or smell. It could be, also, that with the stronger concentrations of repellents other accidental dispersals of mites across the cloths also happened but following more subtle inapparent confusion of their responses than this obvious tumble. It was not practicable to score for this nor, indeed, to witness all cases of violent tumble-reation. The anomalous indications of lower repellency by unwashed treated fabrics than after 3 washes seem to be explicable by stronger concentrations causing misleading escapes across a fabric.

The effect of several washes was further examined by $\chi^{2}$ tests on the repellencies, in the first trial, of the unwashed and the three severally-washed cloths impregnated with the DMP fornulation ( 80 per cent to 100 per cent repellence); differences were not significant. Likewise, there was no significant difference in the corresponding comparison of unwashed and the severally-washed DBP-treated cloths (60 per cent to 100 per cent repellence). It is concluded that, for these repellents, 3 launderings caused no marked deterioration of their repellent efficiency.

With the more fully tested DET-treated cloths, variability is more evident, by inspection. Surprisingly, the unwashed cloth in the first trial gave the lowest repellence of all (22.2 per cent); it remains uncertain how much, if at all, such inefficiency is attributable to incoordination of mite movements since misleading reactions, at least of a 
violent kind as seen with DMP or DBP, were not observed for any DET-treated cloth. A further anomaly is that the most successfully repellent DET-treated cloth, and consistently so, was that washed once (72.7 per cent to 90 per cent repellency) while the consistently lowest repellency was not by the thrice-washed cloth but by that washed only twice ( 30 per cent to 50 per cent repellency).

There is no reason to suppose that interchange of the cloth samples inadvertently occurred. A conclusive interpretation for these anomalous differences is not possible without replication of these tests with parallel samples of cloth separately prepared. It is possible, however, that DET is not only, in general, rather less effective than DMP and DBP but that adequate initial impregnation and/or retention of repellency after launderings is less certainly assured with DET than with the DMP, or DBP, formulations.

So far no account is taken of the contribution to repellence of the benzyl benzoate component of these emulsions containing DMP, DBP or DET; nor was a complete study undertaken of the efficacy of the four chemicals as separate impregnants. However, a patch of cloth impregnated only with undiluted benzyl benzoate, and not washed, gave repellencies of 66 per cent to 75 per cent in 4 trials over 15 weeks. This was a visually oily cloth throughout this period. With $2 \frac{1}{2}$ per cent benzyl benzoateethylan impregnation, corresponding to the benzyl benzoate content in the 5 per cent emulsions containing DMP, DBP or DET, repellence by several treated, unwashed, cloths was 46 per cent to 90 per cent on the day after application, and as negligible as 0 to 40 per cent after 2 weeks; storage as usual was in a polythene envelope except when under test. The DMP, DBP and DET components of the 5 per cent emulsions with benzyl benzoate appear, therefore, to be important to the repellent properties observed.

It may be concluded that although complete repellence was rarely obtained, all three 5 per cent formulations of benzyl benzoate combined with DMP, DBP or DET were, in general, quite effective whether or not the fabric was unwashed or washed 1-3 times after impregnation. The order of effectiveness was DMP $>$ DBP $>$ DET, the DET being less consistently reliable than DMP, or DBP.

\section{Acaricidal Effects}

Repellency was not only rarely complete but more mites escaped across the treated fabrics if the 5 minute test-period was prolonged. For example, repellent efficiency from 4 trials of thrice-washed cloths impregnated with the above 5 per cent emulsions were:-

$\begin{array}{lll}\text { DMP } & 1 \text { st } 5 \text { minutes } & 2 \text { d } 5 \text { minutes } \\ \text { DBP } & 92.9 \text { per cent } & 83.3 \text { per cent } \\ \text { DET } & 83.3 \text { per cent } & 73.8 \text { per cent } \\ \text { D } & 61.4 \text { per cent } & 51.1 \text { per cent }\end{array}$

Clearly, an acaricidal action is desirable to prevent mites which do pass, sooner or later, on to a treated fabric from surviving to attach and feed on a clothed person. This need is, as we have already noted, reflected in the approach of Snyder \& Morton (loc. 
cit) who evaluated the stopping time for trombiculid larvae of cloth impregnated with benzyl benzoate and DBP by placing larvae on treated fabrics and noting the time required for paralysis of the mites. Thus, impregnations of undiluted benzyl benzoate and a 50-50 mixture of this and DBP (at 2-3 gms./sq. $\mathrm{ft}$. of cloth) paralysed the larvae in about 3-4 minutes if cloths had not been washed, and in 15 minutes or more after 5 washings of the treated materials.

Limited observations of acaricidal effects on $O$. bacoti of the 5 per cent DMP, DBP and DET formulations and of benzyl benzoate alone, were as follows:-

\section{5-minute Contact}

Female mites were kept on a treated cloth for 5 minutes and then observed for mortality in wool-plugged glass tubes $(8 \mathrm{~cm}$. $\times 1 \mathrm{~cm}$ ). They died slowly, 50 per cent mortalities - even with unwashed DMP-, DBP-, or DET-treated cloths-being obtained not earlier than 42 hours later, only about 1-2 days sooner than for controls. Undiluted benzyl-benzoate was more efficient causing 50 per cent mortality in 6 to 19 hours. No test was made of the cloth impregnated with the $2 \frac{1}{2}$ per cent benzyl benzoate-ethylan mixture.

\section{Continous Exposure}

When mites were enclosed in a similar glass tube with terminal wool plugs internally faced with untreated control fabric, they burrowed characteristically into folds and crevices of the cloth and, unless disturbed, usually remained there until dead. But, with plugs lined with treated unwashed fabrics, whether of benzyl benzoate alone or this together with DMP, DBP or DET as 5 per cent emulsions, the mites congregated within an hour or so about the middle of the tube. This confirmed the repellent effect of these formulations and was suggestive again of a vapour or smell effect. Mortality in these conditions of apparently continuous exposure, although not continuous contact, were not appreciable within 2 hours. After 24 hours, however, all of 20 mites in tubes with the repellent-surfaced plugs were dead, but only 1 of 18 control mites. With the $2 \frac{1}{2}$ per cent benzyl-benzoate-ethylan impregnation, kill was slower still, some mites being still alive after 48 hours.

The indications from both types of acaricidal test are that several hours were required for any of the repellents to kill $O$. bacoti females. Whether, if on a host for that interval, they would remain sufficiently normal in behaviour long enough to attach and feed was not investigated.

The slower kill of $O$. bacoti adults compared to that observed by Snyder and Morton for trombiculid larvae may be a question of specifically differing susceptibilities to the chemicals. We cannot, however, certainly exclude differences between the experimental procedures or the availability of repellents in the various fabrics used (wool, cotton and, in this study, nylon/cotton materials).

\section{Summary and Conclusion}

Nylon/cotton, jungle-green, uniform cloth impregnated, by dipping, with 5 per cent emulsions of benzyl benzoate and DMP, benzyl benzoate and DBP, or benzyl benzoate and DET ( $\mathrm{N}, \mathrm{N}$-diethyl- $m$-toluamide, DET, deet, metadelphene) proved in laboratory tests to have, in general, good repellency against the Tropical Rat Mite, 
Ornithonyssus bacoti. The rapid running activity of this mite was suitable for comparing, with the apparatus devised, the efficacy of the three formulations in inhibiting the mites from proceeding on to the treated fabrics. Overall repellencies, based on all tests of impregnated fabrics whether subsequently unwashed or washed 1-3 times, "were DMP (85.5 per cent), DBP (79.3 per cent) and DET (60.9 per cent). After 3 launderings, repellent efficiency was still quite good, or very good, as follows: DMP (94.2 per cent), DBP (83.7 per cent) and DET (62.9 per cent). DET appears to be least efficient and, possibly, less reliable than DMP or DBP in initial impregnation and/or in its retention in the cloth during subsequent washings.

Mites survived 5 minutes' contact with any of the three formulations for many hours. Even with continuous exposure, to vapour or smell probably and not to direct contact, most mites survived more than 2 hours. This slow mortality of $O$. bacoti compared to only a few minutes for deaths of trombiculid larvae in contact with benzyl benzoate and DBP, observed by other workers, may well be a measure of the relative insusceptibility of the Tropical Rat Mite rather than, generally, of a poor acaricidal potential for trombiculid larvae of the present repellent formulations.

Conclusive comparison of the relative value of the repellent formulations under study for protection against trombiculid mite infestation and scrub-typhus transmission must ultimately be evaluated with trombiculid larvae. This should be done under field conditions, or simulated field conditions, in which the attachment, or bite, rate on the human host, combining both true repellence and acaricidal effect, is the criterion of effectiveness. Nevertheless, the apparatus as herein devised for use with the Tropical Rat Mite offers a technique sensitive enough for preliminary laboratory observations on repellent (inhibitory) efficiency against mites of candidate chemicals or formulations in different types of cloth, for assay of serial dilutions and other dosage variations of a repellent, or, as in the present work, for comparison of impregnated cloths subjected to different launderings or other exposures which might promote unacceptably rapid loss of repellency.

\section{Acknowledgements}

We wish to thank Mr. M. Hills, B.A., Dip. Stats., of the Department of Medical Statistics and Epidemiology, London School of Hygiene \& Tropical Medicine, for statistical advice; and 43 Command Workshop, Royal Corps of Mechanical and Electrical Engineers, Southern Command, for making the steel parts of the apparatus used.

\section{REFERENCES}

Bertram, D. S., Unsworth, K. and Gordon, R. M. (1946). Ann. trop. Med, Parasit., 40, 228

DetHIER, V. G. (1956). Ann. Rev. Ent., 1, 181.

Dowling, M. A. C. (1955). J. Roy. Army med. Cps., 101, 1.

GILBERT, I. H. (1966). J. Amer. med. Assoc., 196, 253.

GILBERT, I. H., GoUCK, H. K. and SMITH, C. N. (1955). J, econ. Ent., 48, 741.

GoucK, H. K. (1966). Arch. Derm., 93, 112.

GRANETT, P. and SACKTOR, B. (1947). ibid., 40, 259.

HAWking, F. and Sewelx, P. (1948). Brit. J. Pharmacol, 3, 285.

Hocking, B. (1963). Bull. Wid. Hlth. Org. (Suppl.), 29; 121.

Markarion, H., Henry, F. E., and PratT, J. J. (1965). Soap chem. Spec., 41, 94.

SMITH, C. N. (1965). Proc. XIIth Inter. Cong. Ent., London, 1964, 507.

Sмith, C. N. (1966). J. Amer. med. Assoc., 196, 236.

SNYDER, F. M. and MORTON, F. A. (1947). J. econ. Ent., 40, 586.

W. H. O. (1963). Wld. Hlth. Org. tech. Rep. Ser., No. 265. 